Recebido em 11/2016. Aceito para publicação em 10/2017.

\title{
O LUGAR DA MORADIA SOCIAL EM SÃO JOSÉ DOS CAMPOS - SP
}

\section{THE PLACE OF SOCIAL HOUSING IN SÃO JOSÉ DOS CAMPOS - SP}

\author{
Daniela das Neves Alvarenga ${ }^{1}$ \\ Paulo Roamano Reschilian²
}

Resumo: Esta pesquisa propõe uma análise inicial sobre o processo de segregação socioespacial nas cidades europeias pós revolução industrial, a partir da localização da moradia operária nos grandes aglomerados do século XIX. A construção da origem da habitação social nas cidades industriais brasileiras foi feita com enfoque na inserção urbana da moradia produzida pela iniciativa privada e pelo Estado, desde os cortiços do início do século XX, passando pela criação dos Institutos de Aposentadoria e Pensões (IAPs), no governo Vargas, e pelo desenvolvimento do Plano Nacional de Habitação e da criação do Banco Nacional de Habitação (BNH) na década de 1960, até os dias atuais, por meio da Política Nacional de Habitação e do programa Minha Casa Minha Vida (MCMV). Por fim, foi feita uma leitura comparativa da localização das vilas operárias nas primeiras fases de indutrialização da cidade de São José dos Campos, com os conjuntos habitacionais produzidos por meio de parcerias com a Caixa Econômica Federal e com a Companhia de Desenvolvimento Habitacional e Urbano (CDHU), culminando nos empreendimentos produzidos no âmbito do MCMV, voltado às famílias com renda de 0 a 3 salários mínimos, para fins de análise da inserção urbana da moradia social produzida e reflexão sobre a promoção do direito à cidade.

Palavras-chave: Segregação socioespacial; moradia social; urbanização; PMCMV.

Abstract: This research proposes an initial analysis on the process of social and spatial segregation in European cities after the industrial revolution, from the location of the working population in the large agglomerations of the nineteenth century. The construction of the origin of social housing in the Brazilian industrial cities was performed with a focus on the urban insertion of the housing produced by private initiative and the State, from the tenements of the early twentieth century, through the creation of Institutos de Aposentadoria e Pensões (IAPS) in Vargas administration, and the development of the National Housing Plan and the creation of the Banco Nacional de Habitação (BNH) in the 1960s, to the present days by the National Housing Policy and Minha Casa, Minha Vida (MCMV). Finally, a comparative analysis was conducted regarding the location of the workers' villages in the first stages of industrialization of the city São José dos Campos, with the housing estates produced by partnerships with Caixa Econômica Federal and Companhia de Desenvolvimento Habitacional e Urbano (CDHU), culminating in the projects produced under MCMV for families with income of 0 to 3 minimum wages, analyzing the urban insertion of the social housing produced, reflecting on the promotion of the right to the city.

Keywords: Socio-spatial segregation; social housing; urbanization; PMCMV.

\section{INTRODUÇÃO}

Após a Revolução Industrial, as cidades comerciais europeias, lugar de riqueza acumulada na primeira fase do capitalismo, foram palco para instalação das indústrias e da transformação socioespacial decorrente desta.

\footnotetext{
1 Arquiteta e urbanista e mestranda em Planejamento Urbano e Regional da Universidade do Vale do Paraíba UNIVAP, Brasil. E-mail: danielaneves.arq@gmail.com.

2 Arquiteto e urbanista, doutor em Arquitetura e Urbanismo: Estruturas ambientais Urbanas, Docente e pesquisador do Programa de Pós-graduação em Planejamento Regional da Universidade do Vale do Paraíba UNIVAP, Brasil. E-mail: pauloromano@univap.br.
} 
Com a produção industrial em larga escala, mudanças estruturais no papel das cidades foram sendo estabelecidas, não só pelo aumento populacional, mas pela necessidade de constituição de redes urbanas, ampliando o mercado em âmbito regional, nacional e internacional. Cidades como Londres, Birmingham e Manchester, a Bacia do Ruhr, a região da Silésia e Donetsk, foram se estabelecendo nessa nova economia baseada, principalmente, no desenvolvimento industrial, consolidando-se uma crescente especialização funcional, dando início também à divisão territorial do trabalho (SPOSITO, 2004).

De acordo com a autora, essa transformação espacial se tornou efetiva com o desenvolvimento das comunicações e dos transportes. Nasceram os grandes aglomerados urbanos e, com eles, uma grande demanda habitacional direcionada, principalmente, a uma faixa externa ao núcleo central, considerada periferia. Estas periferias foram sendo consolidadas como o lugar de moradia da classe operária nas cidades industriais europeias no século XIX:

Todas as grandes cidades possuem um ou vários «bairros de má reputação» - onde se concentra a classe operária. É certo que é frequente a pobreza morar em vielas escondidas, muito perto dos palácios dos ricos, mas, em geral, designaram-lhe um lugar à parte, onde, ao abrigo dos olhares das classes mais felizes, tem de se safar sozinha, melhor ou pior (ENGELS, 1975)

Peter Hall (2006), ao retratar a condição da classe operária nos cortiços londrinos, discute não só a precariedade das habitações, mas as novas relações sociais estabelecidas após a Revolução Industrial, fazendo com que ricos e classe média passassem a conviver nos grandes centros urbanos, com uma imensa maioria pobre.

No Brasil, a primeira crise de moradias e super-ocupação de habitações vai acontecer na cidade do Rio de Janeiro, quando a capital do país, no final do século XIX, recebe um grande contingente populacional em função da abolição da escravidão, e que irá se abrigar com péssimas condições de moradia nas áreas centrais, em cortiços insalubres (RIBEIRO, 1996).

Na cidade de São Paulo, a falta de habitações para a crescente população urbana no início do século $X X$ foi equalizada pela iniciativa privada, por meio, também, da construção de cortiços, com precárias condições habitacionais (BONDUKI, 1994).

A produção de moradia social, sob a forma de vilas operárias, deu-se inicialmente próximo às fábricas, pelos próprios empresários, em áreas urbanas bem equipadas. $A$ construção das primeiras moradias pelo Estado ocorreu em Recife, em 1926, pela Fundação A Casa Operária. No entanto, a produção de moradia em larga escala ganhou força somente após 1937, com a criação dos Institutos de Aposentadorias e Pensões (IAPs) e, mais tarde, em 1947, com a criação da Fundação da Casa Popular (BONDUKI, 1994). 
O Plano Nacional de Habitação e o Banco Nacional de Habitação (BNH), criados em 1964, também vieram como alternativa ao enfrentamento do déficit habitacional nas grandes cidades brasileiras, principalmente a partir da década de 1970 (BONDUKI, 1994).

A intervenção do Governo do Estado de São Paulo na habitação social se deu a partir de 1967, quando a Companhia Estadual de Casas Populares (CECAP) inicia a produção de habitações para a população de baixa renda. Em 1989, a agência estadual passou a ser denominada Companhia de Desenvolvimento Habitacional e Urbano (CDHU), e é, até hoje, responsável pela construção de moradia popular nas cidades paulistas.

Em 2009, foi criado o programa Minha Casa Minha Vida (MCMV), uma dos eixos do Plano Nacional de Habitação. De acordo com Maricato (2009), o problema habitacional e urbano não tem solução no âmbito do governo federal, pois observa-se no escopo do programa que o mercado imobiliário privado privilegiou a classe média, em detrimento da imensa demanda habitacional, voltada para a população com renda de até três salários mínimos.

Com relação à localização dos empreendimentos, verifica-se que, em geral, os conjuntos habitacionais para população de baixa renda tem sido construídos em locais onde a terra é mais barata, portanto, a longas distâncias do núcleo urbano equipado, acentuando a extensão horizontal das cidades e a segregação urbana (MARICATO, 2009).

Segundo Villaça (1986), a espoliação urbana se dá não só por meio da habitação, mas, especialmente, através da produção do "perto e do longe", entendido como resultado de um processo conduzido pelos homens. O preço da terra e a renda fundiária coloca em evidência a socialização da produção e a apropriação privada do produto do trabalho social.

Cabe ressaltar que, tanto na Europa quanto no Brasil, extemporaneamente, as vilas operárias resultam de uma produção privada de moradia atrelada aos agentes industriais. Num segundo momento, tanto na Europa quanto no Brasil, a questão da moradia é transferida para a responsabilidade do Estado.

A partir das leituras de Sposito (2004), Friedrich Engels $(1845,1887)$ e Peter Hall (2006), foram levantadas questões relativas às cidades industriais europeias e à situação da classe operária no final do século XVIII e início do século XIX, especialmente no que diz respeito à produção de moradia destinada à crescente população que chegava do campo. No Brasil, a falta de habitações nas cidades do Rio de Janeiro, no final do século XIX e de São Paulo, início do século XX, foi estudada por meio das leituras de Ribeiro (1996), Bonduki (1994) e Villaça (1986), introduzindo o programa federal MCMV, com foco na localização dos empreendimentos produzidos para 
população com renda de 0 a 3 salários mínimos, a partir das discussões colocadas por Maricato (2009).

Considerando essa discussão, o artigo tem como objetivo discutir o processo de segregação socioespacial nas cidades industriais, com enfoque no lugar da moradia social, trazendo a discussão para a cidade de São José dos Campos - SP.

Com base no livro "Arquitetura Industrial" (SANTOS, 2006), foi feito o mapeamento das vilas operárias em São José dos Campos nas primeiras fases de industrialização. Os conjuntos habitacionais de interesse social implantados pelo Estado e pela iniciativa privada, a partir da década de 1970, foram levantados com base na dissertação de mestrado de Suriano (2012), e nos dados do programa MCMV-Faixa 1, voltado às famílias com renda de 0 a 3 salários mínimos, fornecidos pela Caixa Econômica Federal (CEF), em 2016.

Uma reflexão sobre o direito à cidade, no seu valor de uso, de vida urbana humana e democrática (LEFEBVRE, 2000), principalmente para a classe trabalhadora, também é inserida no trabalho. A hipótese é que a terra urbana continua sendo tratada como patrimônio, sujeita às pressões do mercado, impedindo o alcance da justiça social e da moradia digna, como vetor de inclusão social.

\section{CONTEXTO DA PRODUÇÃO HABITACIONAL NA EUROPA E NO BRASIL}

A Revolução Industrial foi um processo que se iniciou na Europa, em meados do século XVIII, transformando as cidades comerciais em cidades voltadas à produção industrial. As mudanças estruturais imprimidas pela industrialização e pela produção em larga escala, juntamente ao rápido crescimento populacional dos grandes aglomerados, não foi acompanhado pelo desenvolvimento socioespacial dos centros urbanos:

Cem anos após a Revolução Industrial, o chamado centro guardava sua estrutura original, com seus monumentos, suas ruas estreitas, algumas casas pequenas e compactas, jardins e pátios anexos às residências dos mais ricos. Estes foram abandonando, aos poucos, o centro, onde se amontoavam trabalhadores pobres e recém-migrados do campo. Nos pátios e jardins eram feitas novas construções - casas, indústrias, barracões - tornando a densidade elevadíssima (SPOSITO, 2004).

Segundo Engels (1887), a falta de habitações para os operários, como sintoma da revolução industrial, tornou-se aguda principalmente em Londres, Paris, Viena e Berlim. O autor ressalta que essa falta de habitação atingiu não somente a classe operária, mas também a pequena burguesia, tanto pelo aumento dos aluguéis, quanto pela dificuldade de encontrar alojamento nas grandes cidades modernas. As habitações dos operários, antes localizadas em áreas centrais, foram demolidas para construção de lojas, armazéns e edifícios públicos, como no caso de Paris, com os projetos de reurbanização de Haussmann, ou Londres, Manchester, Liverpool, Berlim e Viena, onde essas 
transformações também ocorreram, empurrando os operários dos centros das cidades para os arredores.

Peter Hall (2006), ao retratar os cortiços londrinos do século XIX, chama a atenção para o fato de se considerar a falta de moradia o problema dos grandes centros urbanos da Europa e dos Estados Unidos, Nova York e Chicago especialmente, em oposição a uma nova série de relações sociais e percepções sociais que nasciam no contexto de industrialização e urbanização nos moldes capitalistas. De acordo com o autor, a diferença é que alguns milhares de ricos e alguns milhões de indivíduos da classe média foram levados a um estreito contato com milhões de pobres e indigentes.

O abandono das formas de controle público sobre o espaço construído agravou o processo de urbanização, levando à manifestação de problemas urbanos, como falta de saneamento, insalubridade, ruas estreitas, moradias precárias e poluição, culminando na separação espacial das classes sociais. Somente na segunda metade do século XIX, o poder público passou a gerir e planejar o espaço urbano, instituindo leis sanitárias. A moradia dos trabalhadores passou a ser construída nos subúrbios, próxima às novas indústrias, seguindo as novas leis definidas pelo poder público, distantes do núcleo urbanizado (SPOSITO, 2004).

No Brasil, os problemas urbanos e a primeira crise de moradias se deu no Rio de Janeiro, no final do século XIX, quando a cidade recebe um grande contingente populacional em função da abolição da escravidão, que irá se abrigar nas áreas centrais, em cortiços insalubres. A adoção de políticas públicas de reurbanização, por meio da "Reforma Passos", com base na ideologia sanitarista, será a resposta do poder público às epidemias que assolavam a cidade. Como consequência dessa política, iniciam-se a construção de casas e loteamentos populares em subúrbios, além do surgimento e crescimento das favelas nos morros da cidade (RIBEIRO, 1996).

Na cidade de São Paulo, a primeira crise habitacional se deu no início do século XX. Essa carência de moradia foi equalizada quantitativamente pela iniciativa privada, através da construção de cortiços insalubres, com precárias condições habitacionais. Os valores dos aluguéis, em sua maioria, ocorriam sem a intervenção do Estado, ficando estabelecidos a partir de contratos particulares firmados entre o locador e o inquilino, com exceção do período de 1921 a 1927, quando houve o congelamento dos aluguéis, por meio da lei do inquilinato (BONDUKI, 1994). Segundo o autor, a atuação da iniciativa privada na construção das "vilas operárias", ocorrida nas décadas de 1920 e 1930, seguida pela produção de moradia por meio dos Institutos de Aposentadoria e Pensões (IAPs), nos anos 40 e 50, com conjuntos habitacionais dotados de equipamentos e serviços coletivos, foram as primeiras iniciativas voltadas ao problema de moradia dos trabalhadores industriais nas grandes cidades brasileiras.

O Plano Nacional de Habitação e o Banco Nacional de Habitação (BNH), criados em 1964, após o Golpe Militar, foram estabelecidos para enfrentamento da crise habitacional, que se intensificava nas grandes cidades brasileiras, principalmente a 
partir dos anos 70. Nesse momento, existiam mecanismos econômicos ligados ao Sistema Financeiro de Habitação, para a aquisição da casa própria ou para construção de novas unidades de interesse social, por meio da iniciativa privada (BONDUKI, 1994).

Em 1949, no estado de São Paulo, foi criada a empresa Companhia Estadual de Casas Populares (CECAP), com o objetivo de produzir habitação social para população de renda baixa. A empresa recebeu mais dois nomes, CODESPAULO E CDH, até receber a atual denominação Companhia de Desenvolvimento Habitacional e Urbano (CDHU).

Com o Plano Estadual de Habitação 2011-2023, a Secretaria de Habitação passou a direcionar as ações em duas linhas: Ações Corretivas, envolvendo projetos em áreas de risco, favelas e assentamentos precários, prevendo a regularização fundiária; e Fomento e Provisão de Moradias, por meio do Fundo Paulista de HIS - Casa Paulista , provisão habitacional e parcerias. O Plano Plurianual (2012-2015) prevê diretrizes e metas ligadas à provisão de moradias, requalificação habitacional e urbana e inclusão social, urbanização de favelas e assentamentos precários, e regularização fundiária de conjuntos habitacionais (SÃO PAULO, 2016).

A partir de 2005, observa-se que a Política Nacional de Habitação (PNH) referese a uma série de encaminhamentos pela busca da garantia dos direitos à moradia e à cidade, tais como: Constituição Federal (CF) de 1988; aprovação do Estatuto da Cidade, em 2001; criação do Ministério das Cidades, em 2003; criação do Sistema Nacional de Habitação de Interesse Social (SNHIS) e do Fundo Nacional de Habitação de Interesse Social (FNHIS), em 2005:

A PNH, delineada a partir de 2005, estabeleceu o maior aporte de recursos já realizados em produção habitacional no País. Esse fato tem impactado decisivamente a (re)estruturação urbana das metrópoles, cidades e regiões brasileiras nos últimos oito anos, sendo importante refletir sobre seus sentidos e tendências (FIGUEIREDO; BALTRUSIS; OLIVEIRA, 2013).

Um dos princípios da atual política está justamente no direito à moradia digna, como vetor de inclusão social. Configura-se como um dos principais instrumentos da $\mathrm{PNH}$, o Plano Nacional de Habitação (PlanHab) e a instituição do programa Minha Casa Minha Vida (MCMV), por meio da Lei Federal no 11.977, de 7 de julho de 2009. No entanto, permanece a mesma lógica do funcionamento do $\mathrm{BNH}$, em que a garantia do trabalho das empreiteiras prevalece frente à construção de cidades mais justas e humanas.

\section{O LUGAR DA MORADIA SOCIAL EM SÃO JOSÉ DOS CAMPOS - SP}

Analisando a a produção de moradia social na cidade de São José dos Campos, sede administrativa da Região Metropolitana do Vale do Paraíba e Litoral Norte - SP, as 
três vilas operárias demarcadas na figura 1 surgiram como iniciativa dos empresários, para os funcionários das primeiras indústrias instaladas no município.

A primeira vila operária foi construída para os funcionários da Tecelagem Parahyba, localizada na Vila Maria, e aconteceu em dois momentos: Vila Velha, construída em 1925, composta por 25 unidades habitacionais; e Vila Nova, construída entre as décadas de 1930 e 1940, localizada em Santana, próxima à Usina de Leite, com 52 moradias. Os proprietários da Cerâmica Weiss II, localizada em Santana, nos anos de 1944 a 1995, construíram uma vila para seus funcionários, localizada nos fundos da fábrica. Já a vila operária da Kanebo, localizada no Jardim América, aconteceu no período conhecido como segunda industrialização, em 1956 (SANTOS, 2006).

A partir de 1976, iniciam-se os programas habitacionais subsidiados pelo Estado na cidade de São José dos Campos, por meio de planos e programas baseados na parceria do governo local com a Caixa Econômica Federal (CEF) e com a Companhia de Desenvolvimento Habitacional e Urbano (CDHU), esta última a partir de 1996. Até 2011, as moradias sociais construídas concentraram-se, principalmente, na periferia da cidade, com exceção de três empreendimentos implantados na Região Central, conforme figura 2, consolidando-se, assim, a segregação socioespacial (SURIANO, 2012).

Figura 1. Vilas operárias na primeira e segunda industrialização, São José dos Campos.

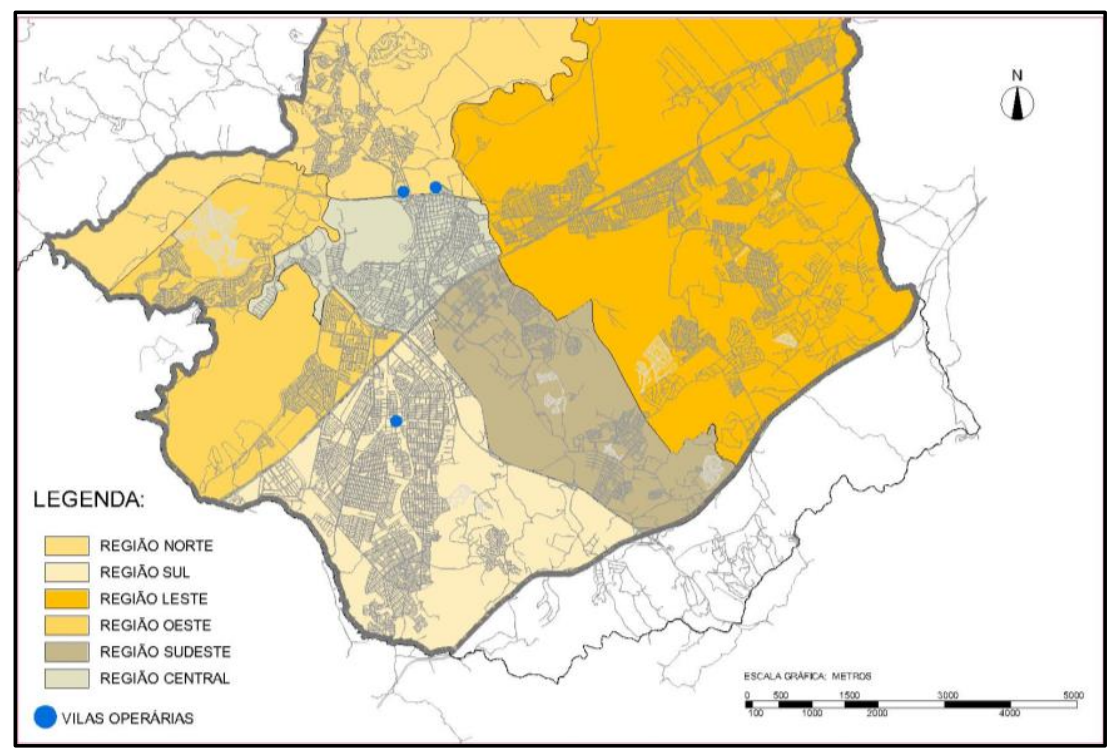

Fonte: Elaborado pelos autores a partir de Santos (2006) e da LC no 306/06, 2016.

A figura 3 traz o mapeamento dos onze conjuntos habitacionais aprovados dentro do MCMV-Faixa 1, a partir de 2013, e aponta para um adensamento na Região Leste: Cajuru I e III, Campos de São José, Colinas I e II e Bom Retiro II, que totalizam 1.318 unidades habitacionais. Apenas quatro conjuntos foram implantados em áreas consolidadas: Limoeiro I e II, próximos ao Jardim das Indústrias, na Região Oeste (588 
unidades) e Colônia Paraíso I e II (528 unidades), ao lado do Parque dos Ipês, na Região Sul. Na Região Norte, foi construído um conjunto, Altos da Ponte (300 unidades), próximo ao Jardim Minas Gerais (CEF, 2016).

Figura 2. Empreendimentos habitacionais (1976 a 2011), São José dos Campos.

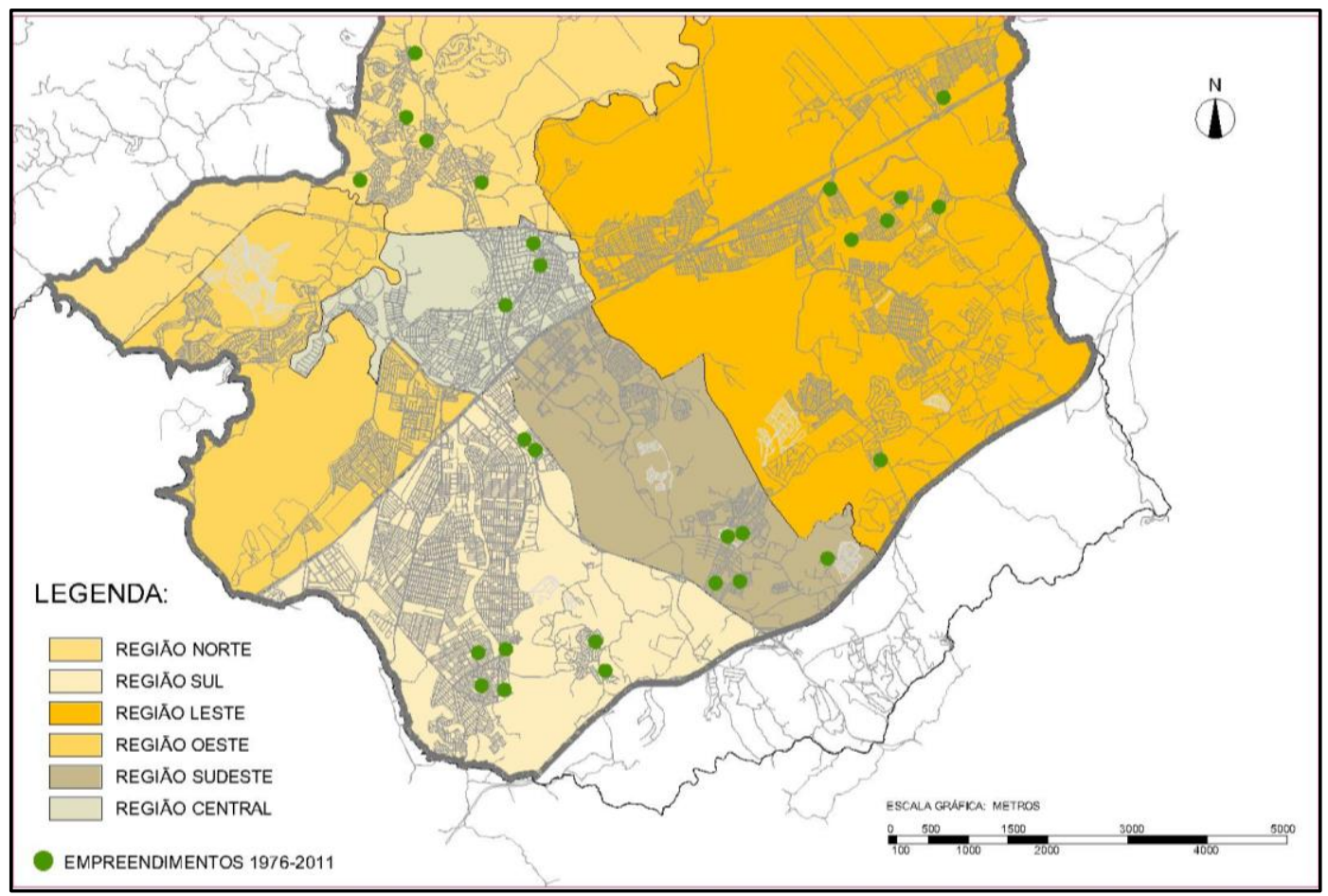

Fonte: Elaborado pelos autores a partir de Suriano (2012) e da LC no 306/06, 2016.

O único loteamento aprovado em São José dos Campos foi o "Pinheirinho dos Palmares II", destinado às famílias removidas do antigo Pinheirinho, ocupação ocorrida em 2004 por trabalhadores sem-teto. O loteamento fica na Região Sudeste, a quase 20 km da Região Central, e foi construído para 1.461 famílias. As 4.195 unidades habitacionais foram aprovadas dentro do programa MCMV, com recursos do Fundo de Arrendamento Residencial (FAR) e do Programa Casa Paulista, do governo do Estado de São Paulo (CEF, 2016).

A concentração de empreendimentos nas periferias da cidade indica a continuidade das dinâmicas segregadoras na formação do espaço urbano, causando o espraiamento da cidade, principalmente nas Regiões Leste e Sudeste, com enfoque à localização do loteamento "Pinheirinho dos Palmares II", figura 4, distante da área central equipada, da vida urbana e da promoção do direito à cidade.

A figura 5 revela a localidade da moradia social produzida na cidade de São José dos Campos, desde as vilas operárias do início do século $\mathrm{XX}$, passando pelas habitações de interesse social construídas a partir de 1976, quando se iniciaram os planos e programas habitacionais na cidade (por meio de parcerias com a CEF e a $\mathrm{CDHU}$ ), até 2016, quando a moradia passou a ser produzida quase que exclusivamente vinculada ao programa MCMV. 
Figura 3. Empreendimentos MCMV (2013 a 2016), São José dos Campos.

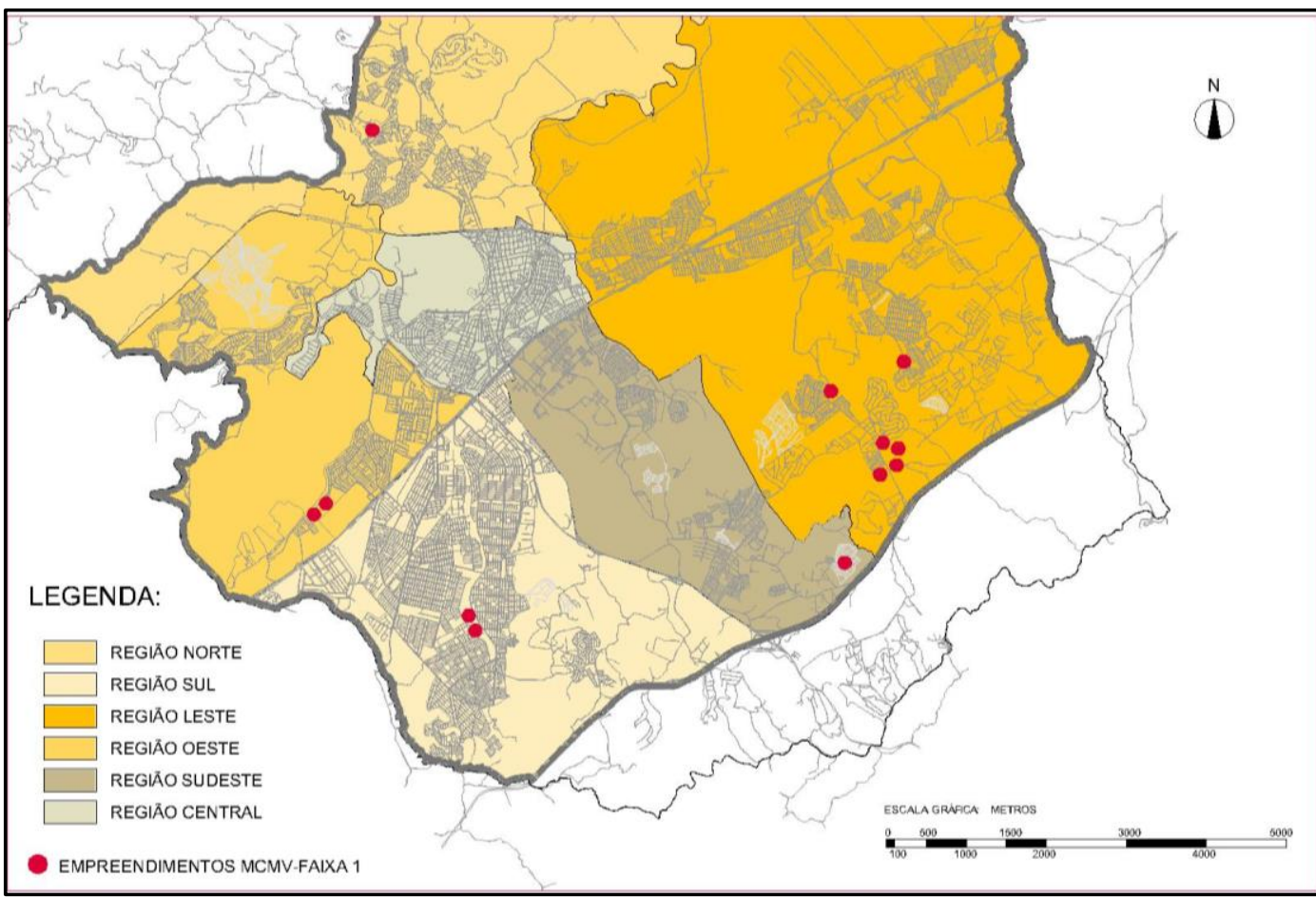

Fonte: Elaborado pelos autores a partir dos dados da CEF e da LC nº 306/06, 2016.

Figura 4. Foto do loteamento Pinheirinho dos Palmares II, São José dos Campos.

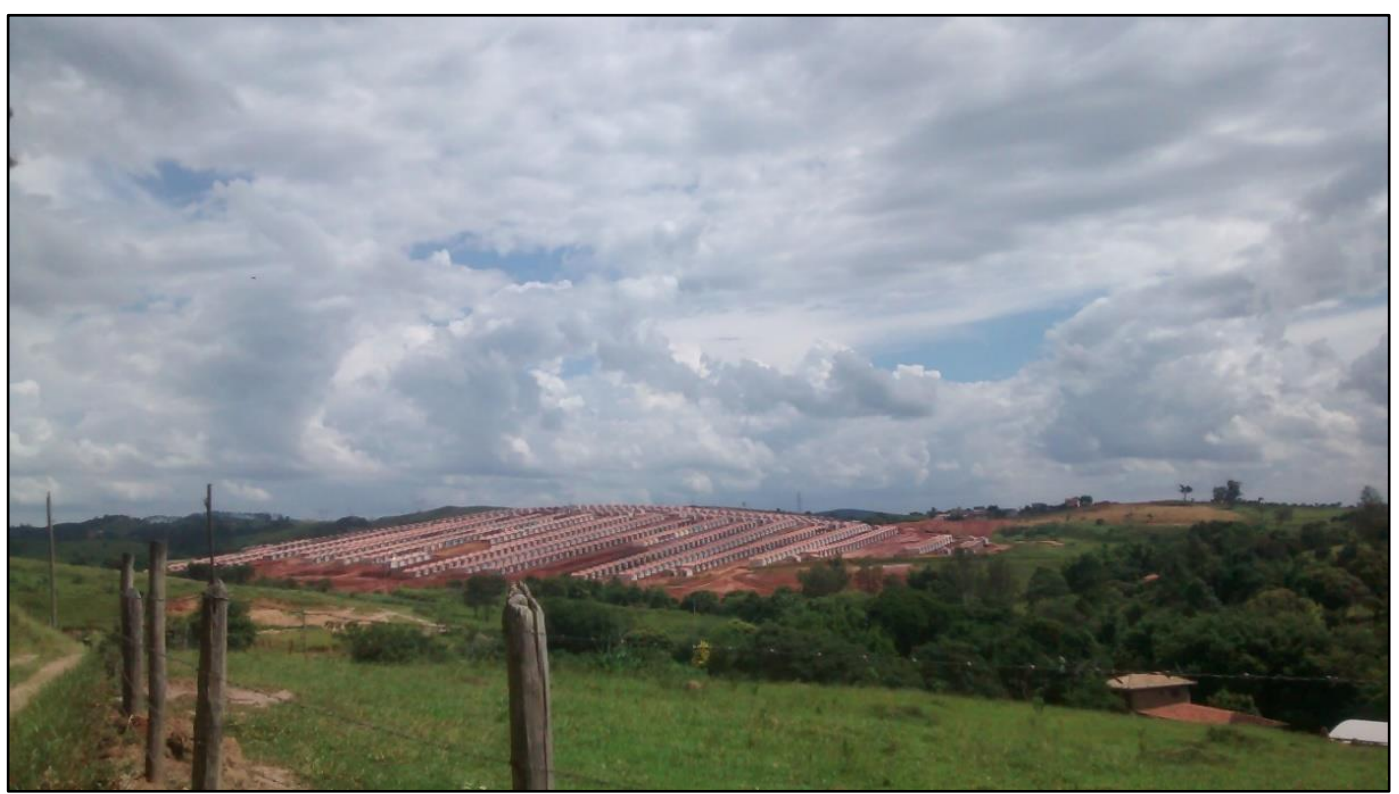

Fonte: Arquivo pessoal, maio de 2016.

Apenas três conjuntos habitacionais foram implantados na Região Central, em parceria com a CDHU. A quase totalidade das habitações concentra-se nas periferias da cidade, afastadas das centralidades dotadas de infraestrutura, equipamentos urbanos, saneamento, transporte público, áreas verdes e espaços de lazer e cultura qualificados. 
Como ressalta Villaça (1986), a questão da moradia não deve se limitar somente à casa. Interessa, principalmente, sua localização, sua vizinhança, os serviços públicos e as distâncias aos locais de emprego. A segregação socioespacial, configurada no tecido urbano até 2011, foi reforçada pela construção dos novos empreendimentos contratados dentro do programa Minha Casa Minha Vida, para a população de até 3 salários mínimos. O espraiamento da cidade e a exclusão social, causados pela própria política pública habitacional, distancia a população mais pobre do direito à cidade, entendida como local de viver.

Figura 5. Moradia Social em São José dos Campos.

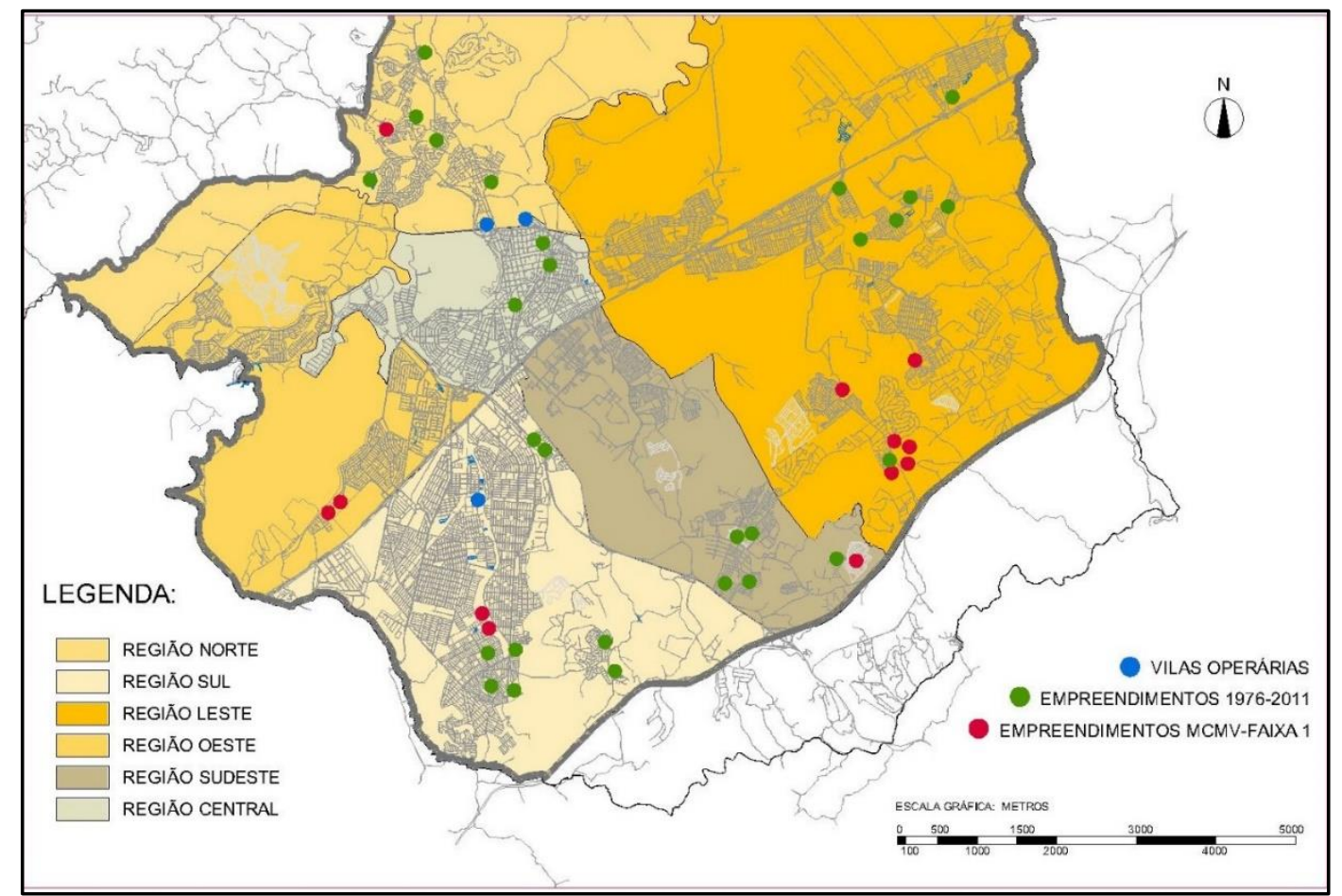

Fonte: Elaborado pelos autores a partir de Santos (2006), Suriano (2012), dados da CEF (2016) e da LC no 306/06: Regiões Geográficas, 2016.

\section{CONCLUSÃO}

A partir das referências analisadas, verificou-se que a localização das vilas operárias europeias se deu dentro de um processo de expansão do núcleo urbano, consolidando-se, então, no subúrbio, ao lado das fábricas. No Brasil, as vilas operárias do início do século XX, principalmente dos anos 1940 e 1950, vão se estabelecer dentro do núcleo urbanizado.

Em São José dos Campos, nota-se que as vilas operárias ocorreram próximas às fábricas e do núcleo urbanizado. No caso da produção habitacional vinculada aos programas habitacionais subsidiados pelo Estado no período de 1976 a 2011, e ao programa MCMV - Faixa 1, a partir de 2013, verifica-se a construção da maioria dos conjuntos na periferia da cidade, na Região Leste, distantes da Região Central. 
Observa-se que, nas grandes cidades europeias pós Revolução Industrial, a produção de moradia social aparece, inicialmente, ligada à preocupação com a produtividade da mão-de-obra. No Brasil, o fator determinante da intervenção estatal parece ser também aquele ligado à economia, ao mercado de trabalho, à geração de emprego e renda. Portanto, como os programas habitacionais não carregam como princípio a garantia do direito à moradia e à cidade, as unidades habitacionais ocorrem quase sempre distantes dos centros, reforçando a segregação socioespacial. Segundo Maricato (2009), o programa MCMV segue na mesma direção, acentuando o processo de espraiamento das cidades e a expulsão dos pobres para periferia, uma vez que os municípios, responsáveis pela regulação do solo, não conseguem deter a prevalência da renda fundiária urbana.

\section{REFERÊNCIAS}

BONDUKI, N. G. Origens da Habitação Social no Brasil. Análise Social, v. 24, n. 127, p. 711-732, 1994.

CEF. GIHABSJ. Dados do PMCMV - faixa 1 na RMVPLN. 2016.

ENGELS, F. A situação da classe trabalhadora na Inglaterra. São Paulo: Global, 1975.

ENGELS, F. Para a questão da Habitação. [s.I]: [s.n], 1887.

FIGUEIREDO, G. C., BALTRUSIS, N., OLIVEIRA, E. Política Nacional de Habitação Hoje. Vistruvius. Revista Arquitextos, n. 14, 2013. Disponível em: <http://www.vitruvius.com.br/revistas/read/arquitextos/14.161/4905>. Acesso em: 15 maio 2016.

HALL, P. Cidades do amanhã: uma história intelectual do planejamento e do projeto urbanos do século XX. São Paulo: Editora Perspectiva, 2006.

LEFEBVRE, H. A produção do espaço. [s.I]:[s.n], 2000.

MARICATO. E. O "Minha Casa" é um avanço, mas segregação urbana fica intocada. Carta Maior, 2009. Disponível em: <http://cartamaior.com.br/?/Editoria/Politica/OMinha-Casa-e-um-avanco-mas-segregacao-urbana-fica-intocada/4/15160>. Acesso em: 03 mai. 2016.

PMSJC, Plano Diretor de Desenvolvimento Integrado (LC oㅜ 306/0). Disponível em: <http://www.sjc.sp.gov.br/media/24458/02lc306regioesgeograficas.pdf>. Acesso em: 10 mar. 2016.

RIBEIRO, Luiz Cesar de Queiroz. Dos cortiços aos condomínios fechados: as formas de produção da moradia na cidade do Rio de Janeiro. Rio de Janeiro: Civilização Brasileira, 1996.

SANTOS, Ademir Pereira dos. Arquitetura Industrial: São José dos Campos. São Paulo: Câmara Brasileira do Livro, 2006. 
SÃO PAULO. CDHU. Programas Habitacionais. 2016. Disponível em:

$<$ http://www.cdhu.sp.gov.br/programas_habitacionais/apresentacao.asp>. Acesso em: 19 jun. 2016.

SPOSITO. M. C. Capitalismo e urbanização. São Paulo: Contexto, 2004. p. 50-60.

SURIANO, A. L. Urbanização, habitação e segregação socioespacial. Revista Univap, v. 18, n. 32, dez. 2012.

VILLAÇA, F. O que todo cidadão precisa saber sobre habitação. São Paulo: Global, 1986. 